\title{
Hyperhomocysteinaemia and premature coronary artery disease in the Chinese
}

\author{
Y I Lolin, J E Sanderson, S K Cheng, C F Chan, C P Pang, K S Woo, J R L Masarei
}

\begin{abstract}
Objectives-To examine the prevalence of hyperhomocysteinaemia and compare it with the classic risk factors and vitamin status in Hong Kong Chinese patients with premature atherosclerotic coronary artery disease.

Design-Case-control study.

Setting-General hospital and community.

Subjects-Forty five patients (39 males) with significant coronary artery disease confirmed by angiography (32 post myocardial infarction) and 23 healthy volunteers (17 male), all aged less than 55 years. Intervention-Standardised methionineloading test.
\end{abstract}

Main outcome measures-Coronary artery disease, risk factors.

Results-More patients than controls had fasting hyperhomocysteinaemia (10/45 $v$ $2 / 23, P=0 \cdot 122$ ), post-methionine hyperhomocysteinaemia $(17 / 45$ v 1/23, $P=$ 0.008 ), and an abnormal response to methionine $(15 / 45 v 1 / 23, P=0.015)$. A history of smoking was more frequent in patients $(3 / 23 v 25 / 45, P=0 \cdot 002)$. Sixteen of 17 patients with hyperhomocysteinaemia but only nine of 28 with normohomocysteinaemia were smokers $(P=$ 0.0002). Fasting plasma cholesterol concentrations (mean (SD)) were higher in hyperhomocysteinaemic patients $(6.41$ $(1.58) \mathrm{mmol} / \mathrm{l})$ than in controls $(5.53(0.90)$ mmol/1) $(P=0.042)$. Serum vitamin B-12 was not reduced and serum folate was higher in hyperhomocysteinaemic patients (35 (4) nmol/1) than normohomocysteinaemic patients $(26(9) \mathrm{nmol} / \mathrm{l})(\mathbf{P}=$ 0.009).

Conclusions-Although the prevalence of hyperhomocysteinaemia in Hong Kong Chinese is similar to that in white subjects, hyperhomocysteinaemia is not an independent risk factor for coronary artery disease and is associated with smoking. This may be of some consequence in view of the change to a more Western diet with more animal protein, and therefore methionine, coupled with a high frequency of cigarette smokers in this region. The causes of the hyperhomocysteinaemia are multifactorial but in this pilot study a deficiency of folate and/or vitamin B-12 did not seem to be one of them.

(Heart 1996;76:117-122)
Keywords: hyperhomocysteinaemia; coronary artery disease; risk factors

Homocysteine is metabolised to cystathionine by pyridoxine dependent cystathionine- $\beta$ synthase and remethylated by folate dependent 5-methyltetrahydrofolate-homocysteinemethyl-transferase with vitamin $\mathrm{B}-12$ as cofactor and by betaine homocysteine methyltransferase $^{1-3}$ to methionine. Classic homocystinuria, due to deficiency of cystathionine$\beta$-synthase, with a prevalence of up to 1:200 000 in white subjects, is associated with premature vascular disease ${ }^{24}$ as are other even rarer inborn errors of homocysteine metabolism. ${ }^{15}$

In recent years mild to moderate hyperhomocysteinaemia has also been found to be associated with premature peripheral vascular, ${ }^{67}$ cerebrovascular, ${ }^{6-8}$ and coronary artery disease, ${ }^{9-11}$ and to be a risk factor independent of hyperlipidaemia, hypertension, or cigarette smoking. ${ }^{12-14}$ In white subjects the prevalence of this risk factor in those with premature vascular disease is about $30 \%$ greater than that in the general population. ${ }^{14-16}$ The causes of mild to moderate hyperhomocysteinaemia include genetic and dietary factors ${ }^{141718}$ with enzyme disorders involved in metabolism to cystathionine, ${ }^{6121920}$ homocysteine remethylation, ${ }^{21}{ }^{22}$ and cofactor deficiency ${ }^{23-25}$ being regarded as the most common.

The prevalence of, and mortality from, coronary artery disease in Chinese subjects is about one-eighth to one quarter of that in white subjects. ${ }^{26}$ However, while the prevalence in the West is falling, in the Southern Chinese $^{2627}$ it is rising and this rise is attributed to the socioeconomic achievements of the past two decades ${ }^{26}$ and a more Westernised lifestyle. Although recent studies confirm the importance of similar risk factors for coronary artery disease in Hong Kong as in the West, ${ }^{27-30}$ the prevalence of hyperhomocysteinaemia is unknown.

Therefore, we have investigated the prevalence of hyperhomocysteinaemia in Hong Kong Chinese with premature occlusive coronary artery disease and have compared it with the prevalence of the classic risk factors in order to ascertain its importance in this population.

Patients and methods

SUBJECTS

We studied 45 patients (39 males, six females), including 13 with ischaemic heart 
disease but no infarction and 32 with a history of myocardial infarction, and 23 apparently healthy controls ( 17 males and four females). All were less than 55 years of age (mean (SD), patients $48 \cdot 2(6 \cdot 6)$ and controls $46 \cdot 1(7 \cdot 3)$, $\mathrm{P}=0 \cdot 192$ ). In all patients occlusive atherosclerotic coronary artery disease was confirmed by coronary angiography one week before methionine loading. The onset of symptoms in patients without infarction was up to two years before angiography. Patients with myocardial infarction were studied up to three years after the initial presentation. Myocardial infarction had been confirmed by serial electrocardiograms and changes in cardiac enzyme activity (serum creatine kinase, aspartate aminotransferase, and lactate dehydrogenase). Methionine loading was delayed until at least three months after the acute event. The controls were hospital staff and their friends and relatives. They were selected on the basis of their age, background, and lifestyle (reflecting similar diets and type of work (mostly white collar workers in the service and other light industries)) and amount of exercise to reflect the characteristics of the patients and this population generally. The exclusion criteria were overt chronic disease including renal and liver insufficiency; acute illness or surgery in the previous three months; alcohol abuse; medication with drugs inducing liver enzymes, lipid lowering drugs, or vitamins; and pregnancy. The study was approved by the institutional human medical ethics committee and informed consent was obtained from all subjects. The procedures followed accorded with institutional guidelines.

\section{METHIONINE LOADING AND BLOOD SAMPLES OBTAINED}

The methionine-loading test with $0 \cdot 1 \mathrm{~g} / \mathrm{kg}$ body weight L-methionine (Scientific Hospital Supplies, Liverpool) was performed as previously described. ${ }^{6}{ }^{12}$ Blood samples were taken for fasting and six hour post-methionine homocysteine; for a full range of laboratory tests to exclude covert disease; and for fasting plasma lipids, serum vitamin B-12, and serum and red blood cell folate concentrations. During the six hours before we took the postmethionine blood sample the subjects were allowed a protein-free diet but they found it unpalatable and continued fasting until the end of the study.

\section{RISK FACTORS}

Hypertension was diagnosed if it was recorded in the patients' medical notes and, in both groups, if the supine systolic pressure was above $160 \mathrm{~mm} \mathrm{Hg}$ and/or the diastolic above $90 \mathrm{~mm} \mathrm{Hg}$ on at least two occasions. Hyperlipidaemia was diagnosed if there was a record in the patients' medical notes of fasting plasma cholesterol and/or triglyceride concentrations above the recommended laboratory reference range in the Hong Kong Chinese population $(5.2 \mathrm{mmol} / \mathrm{l}$ and $1.8 \mathrm{mmol} / 1$, respectively), or if these concentrations were recorded in both groups during the study. We used the results obtained at the time of methionine loading to compare the fasting plasma lipid concentrations and their relation to plasma homocysteine concentrations in both groups. However, to classify patients as hyperlipidaemic or normolipidaemic, we took into account the plasma lipid concentrations in the patients' clinical records, particularly in those on dietary lipid restriction where the results before dietary intervention were used (patients on lipid-lowering drugs had been excluded from the study). Although plasma low density lipoprotein (LDL), high density lipoprotein (HDL), and HDL cholesterol were also measured during methionine loading they are not included because in most cases they were not assayed when the patient originally presented. Smokers included current cigarette smokers or those who had stopped smoking within six months of the start of the study. The smoking status at the time of initial diagnosis and, in ex-smokers, the length of abstinence from smoking were recorded and will be used in follow up studies. No subject smoked cigarettes on the day of methionine loading, and none was a pipe or cigar smoker.

HOMOCYSTEINE ANALYSIS AND DEFINITION OF HYPERHOMOCYSTEINAEMIA

After venesection, blood was immediately put into a heparinised bottle on ice, protected from sunlight, and centrifuged within $10 \mathrm{~min}$ utes. Plasma was stored at $-70^{\circ} \mathrm{C}$ until analysis within six months. The method for total plasma homocysteine measurement was based on those of Ubbink et $a l^{30}$ and Jacobsen et $a l^{31}$ using sodium borohydrate for reduction and dis-association of the amino acid from proteins, trichloroacetic acid for protein precipitation, and SBD-F (ammonium 7fluorobenzo-2-oxa-1,3 diazole-4-sulphonate) for derivatisation of the supernatant) and N[2 mercaptopropionlyl] glycine (Sigma, St Louis, USA) and as an internal standard. Homocysteine was measured by isocratic reverse phase high performance liquid chromatography on a Hewlett Packard HP1090 High Performance Liquid Chromatograph fitted with a HP 1049A fluorescence detector.

The assay was linear to a plasma homocysteine concentration of at least $100 \mu \mathrm{mol} / 1$. The recoveries for homocysteine added to plasma to obtain concentrations of 20,60 , and 80 $\mu \mathrm{mol} / 1$ were 103,91 , and $110 \%$ respectively. The within-batch imprecision (CV\%) ( $\mathrm{n}=16$ for each) was $7 \cdot 8 \%, 6 \cdot 9 \%$, and $3 \cdot 7 \%$ at plasma homocysteine concentrations of 20,60 , and $80 \mu \mathrm{mol} / 1$ respectively. The corresponding between-batch imprecision ( $\mathrm{n}=16$ for each) was $9 \cdot 3 \%, 10 \cdot 6 \%$, and $5 \cdot 2 \%$.

As in previous studies ${ }^{632}$ fasting and post-methionine hyperhomocysteinaemia and methionine intolerance (the rise in plasma homocysteine from the fasting concentration after methionine loading) were considered to be present if plasma homocysteine was above the respective adjusted control mean $+2 S D$. The adjusted control reference range was obtained after removing subjects with values higher than the control mean $+3 S D$ from the 
Table 1 Fasting and post-methionine load plasma homocysteine concentrations, the increase in homocysteine from the fasting concentration after the load, and the prevalence of hyperhomocysteinaemia in controls and patients (geometric means are shown in italics)

\begin{tabular}{|c|c|c|c|c|c|c|}
\hline & \multicolumn{3}{|c|}{ Homocysteine concentration ( $\mu$ molll) } & \multicolumn{3}{|l|}{ Prevalencef } \\
\hline & $\begin{array}{l}\text { Fasting } \\
(\text { mean }(S D))\end{array}$ & $\begin{array}{l}\text { Post-load } \\
\text { (mean (SD)) }\end{array}$ & $\begin{array}{l}\text { Increase } \\
(\text { mean }(S D))\end{array}$ & $\begin{array}{l}\text { Fasting } \\
\text { hyperhomocysteinaemia }\end{array}$ & $\begin{array}{l}\text { Post-methionine } \\
\text { hyperhomocysteinaemia }\end{array}$ & $\begin{array}{l}\text { Pathological } \\
\text { response to } \\
\text { methionine load }\end{array}$ \\
\hline $\begin{array}{l}\text { Control } \\
(n=23)^{\star}\end{array}$ & $\begin{array}{l}12 \cdot 1(4 \cdot 7) \\
11 \cdot 4(1 \cdot 4)\end{array}$ & $\begin{array}{l}29 \cdot 1(9 \cdot 2) \\
27 \cdot 7(1 \cdot 4)\end{array}$ & $17.0(6.3)$ & $1(4 \cdot 3 \%)$ & $1(4 \cdot 3 \%)$ & $1(4 \cdot 3 \%)$ \\
\hline Control & $11 \cdot 3(3 \cdot 6)$ & $27 \cdot 4(7 \cdot 6)$ & $16 \cdot 1(5 \cdot 3)$ & $1(4 \cdot 8 \%)$ & 0 & 0 \\
\hline$(n=21) \dagger$ & $10 \cdot 5(1 \cdot 7)$ & $25 \cdot 1(1 \cdot 2)$ & $14 \cdot 2(1 \cdot 3)$ & & & \\
\hline $\begin{array}{l}\text { Patient } \\
(\mathrm{n}=45)\end{array}$ & $\begin{array}{l}14.9(4.4)(a) \\
14.3(1.4)(f)\end{array}$ & $\begin{array}{l}39 \cdot 1(16 \cdot 3)(b) \\
37.0(1.5)(g)\end{array}$ & $\begin{array}{l}24 \cdot 7(14 \cdot 5)(c) \\
21.8(1 \cdot 6)(h)\end{array}$ & $10(22 \cdot 2 \%)$ & $17(37 \cdot 8 \%)(d)$ & $15(33 \cdot 3 \%)(e)$ \\
\hline
\end{tabular}

^Including all control data

+Without the two control outliers, one with fasting and one with post-methionine homocysteine concentration above the overall control mean +3 (SD).

$\neq$ Calculated using all subjects but with the control mean recalculated after removing the two outliers with homocysteine concentrations above mean +3 (SD).

(a) $\mathrm{P}=0.004$ for patients $v 23$ controls, $\mathrm{P}=0.0008$ for patients $v 21$ controls; (b) $\mathrm{P}=0.003$ for patients $v 23, \mathrm{P}=0.002$ for patients $v 21$ controls; (c) $\mathrm{P}=0.01$ for patients $v 23$ controls, $\mathrm{P}=0.004$ for patients $v 21$ controls, Mann-Whitney test; $(d) \mathrm{P}=0.008$ for patients $v 23$ controls, $\mathrm{P}=0.005$ for patients $v 21$ controls; (e) $\mathrm{P}=0.015$ for patients $v 23$ controls, $\mathrm{P}=0.005$ for patients $v 21$ controls, Fisher's exact test; $(f) \mathrm{P}=0.007$ for patients $v 23$ controls, $\mathrm{P}=0.0001$ for patients $v 21$ controls; $(g) \mathrm{P}=0.003$ for patient $v 23$ controls, $\mathrm{P}=0.0002$ for patients $v 21$ controls; $(h) \mathrm{P}=0.009$ for patient $v 23$ controls, $\mathrm{P}=0.0004$ for patients $v 21$ controls, Student's $t$ test.

original, overall control data and recalculating the mean (and SD).

\section{STATISTICAL ANALYSIS}

The arithmetic means of the fasting, postmethionine homocysteine concentrations, the response to methionine, and other variables between the groups were compared using the Mann-Whitney test and one-way ANOVA. Because the plasma homocysteine concentrations showed a positively skewed distribution, geometric means were also compared, using the independent Student's $t$ test. The correlations between fasting plasma homocysteine, vitamin B-12, serum and red blood cell folate and between fasting plasma homocysteine and fasting lipids were examined using Pearson's correlation coefficients and stepwise linear regression. The prevalence of risk factors in the two groups was compared by Fisher's exact test. To assess whether hyperhomocysteinaemia was associated with coronary artery disease independently of the confounding factors smoking, hyperlipidaemia, and hypertension we used stepwise logistic multivariate regression analysis with coronary artery disease as a binary outcome variable and logarithms of post-methionine plasma homocysteine and presence or absence of high plasma cholesterol and triglyceride concentrations, smoking, and hypertension as independent variables. The statistical analyses were performed using an Abstat software package except for the comparisons of the geometric means of the plasma homocysteine concentrations and the logistic multivariate analysis, both of which were done using a BMDP/Dynamic statistics software package

Table 2 Plasma concentration of vitamin B-12 and folate and of red blood cell folate in controls and patients with and without fasting hyperhomocysteinaemia

\begin{tabular}{lcccc}
\hline & \multicolumn{5}{l}{ Patients } \\
\cline { 3 - 5 } Variable & Controls & All & With & Without \\
\hline Number & 23 & 45 & $10 \dagger$ & 35 \\
$\begin{array}{l}\text { B-12 (pg/ml (SD)) } \\
\text { Red blood cell folate }\end{array}$ & $339(86)$ & $378(159)$ & $378(139)$ & $312(121)$ \\
$\begin{array}{c}\text { (nmol/1 (SD)) } \\
\text { Serum folate }\end{array}$ & $538(273)$ & $675(281)$ & $618(275)$ & $656(229)$ \\
$(\mathrm{nmol} / \mathrm{l}(\mathrm{SD}))$ & $22(10)$ & $30(11)$ & $35(4)^{\star}$ & $26(9)$ \\
\hline
\end{tabular}

$\star \mathbf{P}=0.026$ (ANOVA), $\mathbf{P}=0.009$ (Mann-Whitney) for patients with hyperhomocysteinaemia $v$ those without hyperhomocysteinaemia.

†Multiple linear regression: homocysteine $v \mathrm{~B}-12, \mathrm{r}=0.214, \mathrm{P}=0.359 ;+v \mathrm{RBC}$ folate, $\mathrm{r}=$ $0 \cdot 490, \mathrm{P}=0.072 ;+v$ serum folate, $\mathrm{r}=0.975, \mathrm{P}=0.022$.
(BMDP/Dynamic Release 7·0, (C) 1993, BMDP Statistics Software, Los Angeles, USA). The level of statistical significance was $\mathrm{P}<0.05$.

\section{Results}

HYPERHOMOCYSTEINAEMIA

One control had a fasting and another postmethionine homocysteine concentrations greater than the overall control arithmetic mean $+3 S D$. After removal of these subjects and recalculation of the arithmetric mean there was still one control with fasting hyperhomocysteinaemia but none with post-methionine hyperhomocysteinaemia or abnormal tolerance to homocysteine. The fasting and post-methionine plasma homocysteine concentrations and the rise in homocysteine after methionine were all significantly higher in patients than controls both with $(P=0.0008$, $P=0.002, P=0.01$, respectively) and without $(P=0.004, \quad P=0.003, \quad P=0.004$, respectively) removing the control outliers from the original data (table 1). Similar results were obtained with geometric mean homocysteine concentrations (table 1). Fasting hyperhomocysteinaemia (table 1) was nearly three times more frequent in patients than controls (10 out of $45 v 1$ out of 23 ) but the prevalence was not statistically different between the groups $(P=0 \cdot 122)$, possibly because the numbers were small. Post-methionine hyperhomocysteinaemia and an abnormal response to methionine (table 1) were both significantly more frequent in patients (17 out of $45 v 1$ out of $23, \mathbf{P}=0.008$, and 15 out of $45 v 1$ out of 23, $P=0.015$, respectively). Eight patients had normal fasting but increased post-methionine plasma homocysteine concentrations. One patient had raised fasting and postmethionine plasma homocysteine concentrations but the difference between the two was normal (normal response to methionine).

\section{RELATION BETWEEN}

HYPERHOMOCYSTEINAEMIA AND VITAMIN B-12, FOLATE, AND RED BLOOD CELL FOLATE

Table 2 shows serum vitamin B-12, serum folate, and red blood cell folate concentrations in controls and patients, and patients with and without fasting hyperhomocysteinaemia. Serum 
Table 3 Frequency distribution of hyperlipidaemia, hypertension, smoking, and gender in controls and patients with and without post-methionine hyperhomocysteinaemia and the mean fasting blood lipids on the day of the study

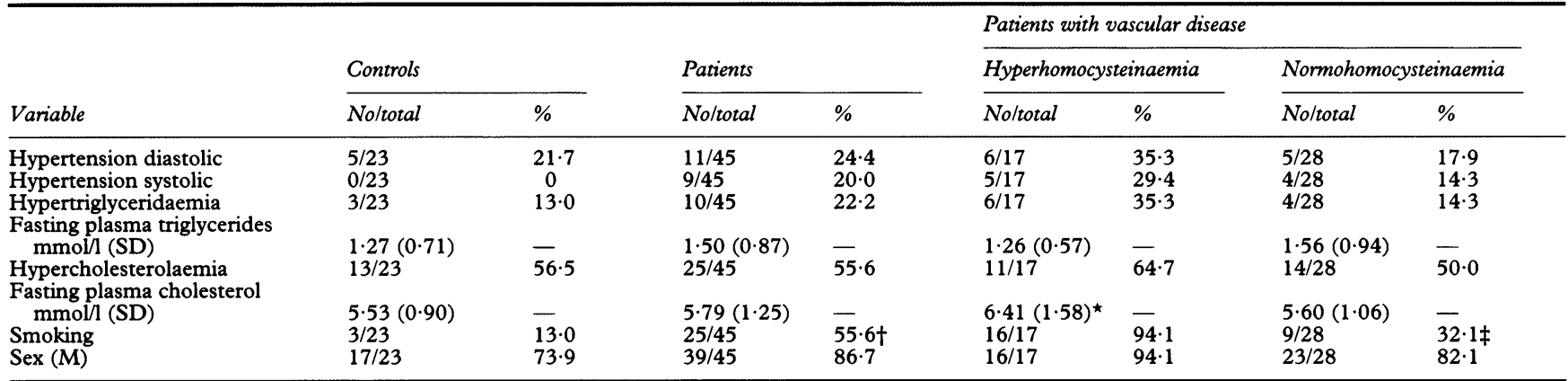

${ }^{\star} \mathrm{P}=0.042$ for patients with hyperhomocysteinaemia $v$ controls (Mann-Whitney).

$\dagger=0.002$ for patients $v$ controls (Fisher's exact test).
$\ddagger P=0.0002$ for patients with $v$ patients without hyperhomocysteinaemia (Fisher's exact test).

folate was higher, though non-significantly, in patients than in controls $(P=0.103)$ and also in hyperhomocysteinaemic patients than in controls $(P=0.092)$. It was, however, significantly higher in patients with than in those without fasting hyperhomocysteinaemia $(P=$ 0.026 by Anova, $P=0.009$ with the MannWhitney test). There were no differences in serum vitamin B-12, serum folate, and red blood cell folate concentrations between patients with $(368 \quad(101) \mathrm{nmol} / \mathrm{l}, 29$ (13) $\mathrm{nmol} / \mathrm{l}, 593$ (223) $\mathrm{nmol} / 1$, respectively) and without post-load hyperhomocysteinaemia (311 (128) pg/l, 26 (10) nmol/l, 686 (251) nmol/l, respectively) or between patients with a normal (322 (127) pg/l, 25 (9) nmol/l, 680 (240) nmol/l, respectively) and abnormal methionine tolerance (351 (108) pg/l, 28 (11) $\mathrm{nmol} / \mathrm{l}, 587$ (253) nmol/l). Further, on comparison of the correlations between concentrations of homocysteine and vitamins in the various groups, there was a trend towards a positive correlation between fasting homocysteine and serum folate concentrations in patients with fasting hyperhomocysteinaemia $(r=0.779, P$ $=0.068)$ and a positive correlation with multiple linear regression using fasting homocysteine as the dependant variable and adding first vita$\min \mathrm{B}-12(\mathrm{r}=0.2139, \mathrm{P}=0.359)$, followed by red blood cell folate $(r=0.490, P=0.72)$, and then serum folate $(r=0.975, P=0.022)$. This was not observed with the other groups.

No subject had a reduced serum vitamin B12 concentration. One control with normohomocysteinaemia had a reduced serum folate concentration. Eight controls $(34.8 \%)$ and five patients $(11 \cdot 1 \%)$, with no significant difference in the distribution between the main groups or between those with and without hyperhomocysteinaemia, had low red blood cell folate.

HYPERHOMOCYSTEINAEMIA AND CONVENTIONAL RISKS FOR CORONARY ARTERY DISEASE

Table 3 shows the frequency distribution of hyperlipidaemia, hypertension, and cigarette smoking in controls and patients with postmethionine hyperhomocysteinaemia, and the mean fasting plasma cholesterol and triglyceride concentrations. A history of cigarette smoking was the only risk factor that was significantly more frequent in patients $(P=0.002)$. Further, a history of smoking was obtained in all but one patient with hyperhomocys- teinaemia and in only a third of those without $(P=0.0002)$. All the smokers were male. When we removed the female subjects from the groups the higher prevalence of smoking in patients with hyperhomocysteinaemia remained significant $(P=0.0004)$. There was no difference in fasting plasma lipids between the groups when we used Anova, but with the Mann-Whitney test plasma cholesterol was higher in patients with hyperhomocysteinaemia than in controls $(P=0.042)$. No correlation was obtained between plasma homocysteine and plasma lipids in either group when we used simple regression or stepwise multiple linear regression. However, with stepwise logistic regression, coronary artery disease as a binary outcome, and hyperhomocysteinaemia and other risk factors as independent variables, only smoking was found to be a significant independent variable (for smoking $P=0.0004$, for plasma homocysteine concentrations $P=$ $0 \cdot 1394$, for the blood pressure $P=0.9224$, for plasma cholesterol concentration $P=0.4140$, for plasma triglyceride concentrations $P=$ $0 \cdot 2144)$.

\section{Discussion}

Since the first report, in $1976^{33}$ of an association between mild hyperhomocysteinaemia and premature coronary artery disease, accumulated reports to date have shown a prevalence of mild to moderate homocysteinaemia in $12 \%$ to $40 \%$ of patients with premature vascular disease. ${ }^{14} 18$ This prevalence seems to vary with the anatomical site and has been reported to be highest in cerebrovascular and lowest in coronary artery disease. $^{14}$

Studies in white subjects have shown fasting hyperhomocysteinaemia in $11 \%$ to $24 \%^{9} 1013$ and post-methionine hyperhomocysteinaemia in $14 \%$ to $30 \%{ }^{11}{ }^{12} 34$ of subjects with premature coronary vascular disease. Our findings suggest that hyperhomocysteinaemia may be at least as common in Hong Kong Chinese patients. The plasma homocysteine concentrations were also similar to those reported in white subjects. ${ }^{92235}$ Although this is the first report on hyperhomocysteinaemia in a Chinese population, increased homocysteine concentrations have also been noted in Japanese patients with vascular disease. ${ }^{36} 37$

Mild to moderate hyperhomocysteinaemia is 
associated with both genetic and nutritional factors. In one study post-methionine homocysteine concentrations were comparable to those in subjects with obligate heterozygosity for cystathionine- $\beta$-synthase in $18(30 \%)$ out of 60 patients with coronary artery disease. ${ }^{12}$ Others have noted reduced concentrations of cystathionine- $\beta$-synthase in most of their patients with premature vascular disease and hyperhomocysteinaemia. ${ }^{17} \mathrm{~A}$ thermolabile variant of methylenetetrahydrofolate reductase, with $50 \%$ of the activity of the normal enzyme, was noted in about $8 \%$ of patients without, $13 \%$ with moderate, and $18 \%$ of those with severe coronary artery occlusion. ${ }^{22}$ In the general population the prevalence of heterozygosity for cystathionine- $\beta$-synthase is up to about $1 \%$ and that of thermolabile methylenetetrahydrofolate reductase up to about $5 \%,{ }^{21}$ suggesting that these enzymes may be a major cause of genetic hyperhomocysteinaemia. Genetic factors influencing homocysteine metabolism may also be involved in about $10 \%$ of cases of early familial coronary artery disease. ${ }^{9}$ Nutritional deficiency of vitamins B-12 and B-6 and, particularly, folate may be even more important. Blood folate ${ }^{31213}$ and, less frequently, blood vitamin B-12312 $2^{34}$ and B-6 ${ }^{11}{ }^{13}{ }^{35}$ concentrations have been shown to be inversely related to basal plasma homocysteine concentrations. Further, vitamin treatment normalises homocysteine concentrations, ${ }^{17} 3839$ though it is not yet known if this also reduces the risk of coronary artery disease. ${ }^{1323}$ However, nutritional folate deficiency is thought to be present in up to $40 \%$ of the US population and prophylaxis with increased dietary intake of folate has already been suggested. ${ }^{23}$

Methionine loading has been often used to unmask methionine intolerance in patients with normal fasting plasma homocysteine concentration. ${ }^{11}$ It has also been used to distinguish between causes of hyperhomocysteinaemia. Though fasting hyperhomocysteinaemia has been reported in association with vitamin deficiencies, ${ }^{14} 32$ with the heat labile form of methylenetetrahydrofolate reductase, ${ }^{22}$ and with post-methionine hyperhomocysteinaemia caused by heterozygous cystathionine- $\beta$-synthase, ${ }^{36712}$ these distinctions are not clear-cut. Subnormal activity of cystathionine$\beta$-synthase can be caused by vitamin B- 6 deficiency alone. ${ }^{38}$ The co-existence of heterozygosity for the enzyme and deficiency of vitamins B-6 and B-12 and/or folate has been reported. ${ }^{11217}$ Methionine intolerance associated with normal activity of cystathionine- $\beta$ synthase but with folate deficiency has also been noted. ${ }^{12}$ In a recent study in patients with post-methionine hyperhomocysteinaemia and with normal blood concentrations of B-6, B-12, and folate, in most the response to methionine loading became normal after treatment with vitamin supplements. ${ }^{38}$ This suggested that the patients who responded to B- 6 might have been heterozygous for cystathionine- $\beta$-synthase whereas the non-responders might have had the heat labile form of methylenetetrahydrofolate reductase.

We did not assay the activities of cystathion- ine- $\beta$-synthase or thermolabile methylenetetrahydrofolate reductase, or measure blood concentrations of B-6. Thus the predominant cause(s) of hyperhomocysteinaemia in our patients is unknown. Further, the study was limited by the number of subjects, particularly controls. Premature coronary vascular disease is relatively rare in the Hong Kong Chinese. In addition, recruiting volunteers for the study, especially for methionine loading, was difficult in this community because it entailed a prolonged fast because the subjects found the protein free meals unpalatable. However, the results of this study differed from most previous reports in two major aspects. Firstly we noted higher plasma folate concentrations in hyperhomocysteinaemic than normocysteinaemic subjects as well as a positive correlation between plasma folate and fasting homocysteine concentrations in those who were hyperhomocysteinaemic. This was unexpected and contradicted previous reports.31213 The patients denied being on vitamin supplements. Although in this community green, leafy, lightly steamed vegetables (for example, broccoli, Chinese white and flowering cabbage, Chinese kale, Chinese asparagus) are commonly eaten throughout the year (probably more than in the West, personal observation) and folate deficiency is generally rare, the concentrations should have been similarly high in all groups. A possible explanation for these findings may be that these patients have a generally higher intake of green vegetables, meat, and animal fat than other subjects in the study, since they also had higher fasting plasma cholesterol concentrations and also higher plasma B12 concentrations (though this difference was not significant). This is being investigated and requires confirmation with larger subject numbers. The prevalence of the thermolabile methyltetrahydrofolate reductase is also being examined in this population. Secondly, we noted a strong correlation between hyperhomocysteinaemia, smoking, and coronary artery disease. However, only smoking was found to be an independent risk factor, suggesting that the association between hyperhomocysteinaemia and coronary artery disease was likely to be the result of the higher prevalence of smokers in the hyperhomocysteinaemic group in this cohort or an interaction between the two risk factors. This needs further study. Previously, hyperhomocysteinaemia was thought to be an independent risk factor for vascular disease. ${ }^{1213}$ Although the association with smoking in this study could be coincidental because the numbers of subjects were small, it was also recently seen in white subjects with hyperhomocysteinaemia and occlusive vascular disease. ${ }^{3540} \mathrm{~A}$ weak association with hypercholesterolaemia had also been noted by some but not other workers. ${ }^{41}$

Classic coronary artery disease risk factors are as important in the Hong Kong Chinese as in the Western population, although at present hypertension and cigarette smoking may be more important. ${ }^{27-29}$ Whereas the incidence of coronary artery disease and myocardial infarction is falling in the West generally and more 
particularly in the higher socioeconomic classes, in the Southern Chinese the trend is in the opposite direction. ${ }^{26}{ }^{27}$ Increased affluence, a change to a more sedentary Western lifestyle, to a diet richer in animal and diary products, particularly in the younger generations, and cigarette smoking are thought the main reasons. ${ }^{26}$ Proteins of animal origin contain two to three times more methionine than proteins of plant origin. The aetiology of hyperhomocysteinaemia is multifactorial but the results of this study suggest that in this population vitamin deficiency is unlikely to be a cause. Defective utilisation of folate is possible but genetic disorders involved in homocysteine metabolism, already shown to be common in white subjects, are more likely. While heterozygosity for homocystinuria caused by cystathionine synthase deficiency or the presence of the thermolabile methylenetetrahydrofolate reductase as a risk factor should remain constant, it may not have been of significance in this population until compounded with a high methionine diet and, possibly, smoking.

In conclusion, the results of this study, although in a small number of subjects, suggest that the prevalence of hyperhomocysteinaemia in the Hong Kong Chinese with coronary artery disease is similar to, and possibly higher, than in the West. Absence of overt vitamin B-12 and folate deficiency and the presence of high folate concentrations in hyperhomocysteinaemic patients suggest that vitamin deficiency was unlikely to be of major aetiological importance. The cause for the higher folate concentrations in hyperhomocysteinaemic patients is being investigated. An association between hyperhomocysteinaemia and smoking was also noted with only smoking being an independent variable for coronary vascular disease. This needs further evaluation.

1 Skovby F. Inborn errors of metabolism causing homocys1989;19(suppl 1):4-9.

2 Wilcken DEL, Dudman NPB. Mechanisms of thrombogenesis and accelerated atherogenesis in homocysteinaemia. Haemostasis 1989;19(suppl 1):14-23.

3 Brattström L, Israelsson B, Hultberg B. Plasma homocysteine and methionine tolerance in early-onset vascular disteine and methionine tolerance in early-onset

4 Cacciari E, Salardi S. Clinical and laboratory features of homocystinuria. Haemostasis 1989;19(suppl 1):10-13.

5 Visy JM, Le Coz P, Chadefaux B, Fressinaud C, Woiman $\mathrm{F}$, Marquet J, et al. Homocystinuria due to 5,10-methylenetetrahydrofolate reductase deficiency revealed by stroke in adult siblings. Neurology 1991;41:1313-5.

6 Boers GHJ, Smals AGH, Trijbels FJM, Fowler B, Bakkeren JAJM, Schoonderwaldt HC, et al. Heterozygosity for homocystinuria in premature peripheral and cerebral occlusive arterial disease. $N$ Engl $₹$ Med 1985;313:709-15.

7 Boers GHJ. Carriership for homocystinuria in juvenile vascular disease. Haemostasis 1989;19(suppl 1):29-34.

8 Brattström LE, Hardebo JE, Hultberg BL. Moderate homocysteinaemia-a possible risk factor for arteriosclerotic cerebrovascular disease. Stroke 1984;15:1012-6.

9 Wu LI, Wu J, Hunt SC, James BC, Vincent GM, William $\mathrm{RR}$, et al. Plasma homocyst(e)ine as a risk factor for early familial coronary artery disease. Clin Chem 1994;40: 552-61

10 Israelsson B, Brattström L, Hultberg B. Homocysteinaemia and myocardial infarction. Atherosclerosis 1988;71:227-33.

11 Murphy-Chutorion DR, Alderman EL. The case that hyperhomocysteinaemia is a risk factor for coronary artery disease. Am ₹ Cardiol 1994;73:705-7.

12 Clarke R, Daly L, Robinson K, Naughten E, Cahalane S Fowler B, et al. Hyperhomocysteinaemia: An independent risk factor for vascular disease. $N$ Engl 7 Medicine 1991;324:1149-55.

13 Stampfer MJ, Malinow MR, Willet WC, Newcomer LM, Upson B, Ullmann D, et al. A prospective study of plasma physicians. $\mathcal{F A M A} 1$ 1992;268:877-81.

14 Ueland PM, Refsum H, Stabler SP, Malinow MR
Andersson A, Allen RH. Total homocysteine in plasma or serum: methods and clinical applications. Clin Chem 1993 39:1764-79.

15 Malinow MR. Hyperhomocyst(e)inemia. A common and easily reversible risk factor for occlusive atherosclerosis. Circulation 1990;81:2004-6.

16 Ueland PM, Refsum H, Brattström L. Plasma homocysteine and cardiovascular disease. In: Francis RB Jr, ed. Atherosclerotic cardiovascular disease, haemostasis, and 183-236.

17 Dudman NP, Wilcken DE, Wang J, Lynch JF, Macey D, Lundberg P. Disordered methionine/homocysteine metabolism in premature vascular disease. Its occurrence, cofactor therapy, and enzymology. Arterioscler Thromb 1993; tor therapy,

18 Malinow MR, Stampfer MJ. Role of plasma homocyst(e)ine in arterial occlusive disease. Clin Chem 1994;40:857-8.

19 Wilcken DEL, Reddy SG, Gupta VJ. Homocysteinemia ischemic heart disease and the carrier state for homocystinuria. Metabolism 1983;32:363-70.

20 Boers GHJ, Fowler B, Smals AGH, Trijbels FJ, Leermarkers AI, Kleijer WJ, et al. Improved identification of heterozygotes for homocystinuria due to cystathionine synthase deficiency by the combination of methionine loading and enzyme determination in cultured fibroblasts. Hum Genet 1985;69:164-9.

21 Kang S-S, Wong PWK, Susmano A, Sora J, Norusis M, Ruggie $\mathrm{N}$. Thermolabile methylenetetrahydrofolate reductase:an inherited risk for coronary artery disease. $A m ~ F$ Hum Genet 1991;48:536-46.

22 Kang S-S, Passen EL, Ruggie N, Wong PWK, Hyunchoo S. Thermolabile defect of methylenetetrahydrofolate reductase in coronary artery disease. Circulation 1993;88. 1463-9.

23 Stampfer MJ, Malinow MR. Can lowering homocysteine levels reduce cardiovascular risk. $N$ Engl f Med 1995;332: 328-9.

24 Brattstrom L, Israelsson B, Lindgarde F, Hultberg B. Higher total plasma homocysteine in vitamin B12 deficiency than in heterozygosity for homocystinuria due to cystathionine $\beta$-synthase deficiency. Metabolism 1988;37:175-8.

25 Brattström LE, Israelsson B, Jeppsson J-O, Hultberg BL Frattstrom LE, Israelsson B, Jeppsson J-O, Hultberg BL. Folic acid-an innocuous means to reduce plasma

26 Woo KS, Donnan SPB. Epidemiology of coronary arterial disease in the Chinese. Int $\mathcal{F}$ Cardiol 1989;24:83-93.

27 Donnan SPB, Ho SC, Woo J, Wong SL, Woo KS, Tse CY, al. Risk factors for acute myocardial infarction in a souther Chinese population. Ann Epidemiol 1994;4(1):46-58.

28 Woo KS. Epidemiology of ischaemic heart disease and coronary risk factors in Hong Kong. Bull f Hong Kong Med Ass 1984;36:73-82.

29 Woo J, Ho SC, Wong SL, Woo KS, Tse CY, Chan KK, et al. Lipids, lipoproteins and other coronary risk factors in Chinese male survivors of myocardial infarction. Int $\mathcal{F}$ Cardiol 1993;39:195-202.

30 Ubbink JB, Vermaak WJH, Bissbort S. Rapid high performance liquid chromatography assay for total homocystein levels in human serum. $\mathcal{f}$ Chromatography 1991;565 441-6.

31 Jacobsen DW, Gatautis VJ, Green R. Determination of plasma homocysteine by HPLC with fluorescence detection. Analytical Biochemistry 1989;178:208-14.

32 Andersson A, Brattström L, Israelsson B, Isaksson A Hamfelt A, Hultberg B. Plasma homocysteine before and after methionine loading with regard to age, gender and menopausal status. Eur f Clin Invest 1992;22:79-87.

33 Wilcken DEL, Wilcken B. The pathogenesis of coronary artery disease: A possible role for methionine metabolism. $\mathcal{F}$ Clin Invest 1976;57:1079-82.

34 Murphy-Chutorian DR, Wexman MP, Grieco AJ, Heiniger JA, Glassman E, Gaull GE, et al. Methionine intolerance: JA, Glassman E, Gaull GE, et al. Methionine intolerance: a possible risk factor for

35 Mansoor AM, Beromark C, Svardal AM, Lonning PE, Ueland. Redox status and protein binding of plasma homocysteine and other aminothiols in patients with earlyonset vascular disease. Homocysteine and peripheral vascular disease. Arteriosclerosis, Thrombosis and Vascular Biology 1995;15:232-40.

36 Araki A, Sako Y, Fukushima Y, Matsumoto M, Asada T, Kita $T$. Plasma sylfhydryl-containing amino acids in patients with cerebral infarction and in hypertensive patients. Atherosclerosis 1989;79:139-46.

37 Araki A, Sako Y, Ito H. Plasma homocysteine concentration in Japanese patients with non-insulin-dependent diabetes mellitus; effect of parenteral methylcobalamin treatment. Atherosclerosis 1992;103:149-57.

38 Franken DG, Boers HJ, Blom HJ, Trijbels FJM, Kloppenborg PWC. Treatment of mild hyperhomocysteinaemia in vascul

39 Wilcken DEL, Dudman NPB Tyrrell PA. Homocystinuria due to cystathionine- $\beta$-synthase deficiency - the effects of betaine treatment in pyridoxine-responsive patients. Metabolism 1985;34:1115-21.

40 Bergmark C, Mansoor MA, Swedenborg J, de Faire U, Svardal AM, Ueland PM. Hyperhomocysteinaemia in patients operated for lower extremity ischaemia below the age of 50: effect of smoking and extent of disease. Eur Vasc Surg 1993;7:391-6.

41 Malinow MR. Frontiers in medicine: Homocyst(e)ine and arterial occlusive disease. $\mathcal{f}$ Int Med 1994;236:603-17. 